\title{
Violence-related injury in emergency departments in Brazil
}

\author{
Vilma Pinheiro Gawryszewski, ${ }^{1}$ Marta Maria Alves da Silva, ${ }^{2}$ \\ Deborah Carvalho Malta, ${ }^{2}$ Scott R. Kegler, ${ }^{3}$ James A. Mercy, ${ }^{3}$ \\ Márcio Dênis Medeiros Mascarenhas, ${ }^{2}$ \\ and Otaliba Libânio Morais Neto ${ }^{2}$
}

$\begin{array}{ll}\text { Suggested citation } & \begin{array}{l}\text { Gawryszewski VP, Silva MMA, Malta DC, Kegler SR, Mercy JA, Mascarenhas MD, et al. Violence- } \\ \text { related injury in emergency departments in Brazil. Rev Panam Salud Publica. 2008;24(6):400-8. }\end{array}\end{array}$

ABSTRACT Objective. This article describes the characteristics of violence-related injury (VRI) cases presenting at emergency departments (EDs) in Brazil and compares circumstances for assaultrelated and self-inflicted cases.

Methods. The study is cross-sectional. The data describe cases seen in September 2006 in 62 EDs, representing all 26 states and the Federal District. A total of 4835 case records were analyzed. Basic statistical tabulations were complemented by logistic regression analysis to assess potential associations between type of violence (assault or self-harm) and multiple factors. Results. Males comprised $72.8 \%$ of cases while those aged 20 to 29 comprised $35.4 \%$. Alcohol use was reported or suspected in $42.7 \%$ of cases, more commonly among males. Assault victims comprised $91.4 \%$ of cases versus self-inflicted injuries, which accounted for $8.6 \%$. Threefourths of the assault victims were male, while over half of the self-inflicted injury victims were female. The leading mechanism for assaults was physical force/blunt objects (46.2\%), whereas poisoning was the predominant mechanism for self-inflicted injuries (71.4\%). Younger females were significantly more likely to have been victims of self-inflicted injuries than younger males, while younger males were more likely to have been victims of assault; this finding is more pronounced in cases where alcohol use was reported. Self-inflicted injuries were significantly more likely to occur in residences, while assaults were more likely to occur away from home.

Conclusion. These results can improve understanding of the scope and characteristics of VRIs in Brazil (and thus contribute to national injury prevention efforts), and help identify areas for future research.

Key words Emergency medical services, violence, aggression, suicide, Brazil.

1 (At the time of the study) Injury Prevention Coordinator, São Paulo State Health Department, São Paulo-SP, Brazil; present affiliation: Regional Technical Advisor, Sustainable Development and Environmental Health Area, Pan American Health Organization, Washington, DC, United States of America. Send correspondence and reprint requests to: Vilma Pinheiro Gawryszewski, Av. Dr. Arnaldo 351, Sala 609, CEP 01246000, São Paulo, SP, Brazil. E-mail: vilmapg@saude.sp.gov.br
2 General Coordination of Noncommunicable Diseases and Illnesses, Department for Analysis of Health Conditions, Health Surveillance Secretariat (CGDANT/DASIS/SVS), Ministry of Health, Brasília-DF, Brazil.

3 Division of Violence Prevention, National Center for Injury Prevention and Control, Centers for Disease Control and Prevention, Atlanta, GA, United States of America.
Violence has become a major concern for Brazilian society. Over the period from 1980 to 2002, homicide rates more than doubled in Brazil (1). This change affects the quality of life by increasing the feeling of being unsafe, especially among those living in urban areas. Increasing violence also 
challenges the health sector. Data from the World Health Organization (WHO) World report on violence and health (2) indicate Brazil's homicide rate is one of the highest in the world. As set forth in the report, an important step in the public health approach to violence prevention is gaining "as much basic knowledge as possible about all the aspects of violencethrough systematically collecting data on the magnitude, scope, characteristics and consequences ..." (2: 4). Collection and analysis of data from health systems is an important component of this process and a valuable tool in informing efforts to address public health and social problems such as violence.

In Brazil, deaths and admissions to public hospitals due to violencerelated injuries (VRIs) are monitored using official information systems. The resulting data sets are managed by the Brazilian Ministry of Health and can be easily accessed (3). The data underscore the substantial impact that violence has on the Brazilian population, and establish this issue as both a public health and a social problem that must be remedied. Prior analysis of these data showed that in 2005 there were 56128 deaths due to VRIs (with a corresponding crude annual mortality rate of 30.4/100 000) and among these deaths homicides were predominant (3). In the same year there were also 57635 victims of violence admitted to Brazilian public hospitals (with a corresponding crude annual rate of 31.3/100 000) (3).

In 2006, to supplement existing data sources, Brazil's Ministry of Health led the implementation of a new national surveillance system, the Emergency Department Injury Surveillance System (Sistema de Vigilância de Violências e Acidentes, VIVA) to collect data on injury-related cases seen in hospital emergency departments (EDs). This article describes the characteristics of VRI cases presenting in selected EDs in Brazil during the month of September 2006 and compares demographic characteristics and circumstances for assault-related cases to those for cases involving self-harm.

\section{MATERIALS AND METHODS}

\section{Case definitions}

The current study adopted the following WHO definition for violence: "The intentional use of physical force or power, threatened or actual, against oneself, another person, or against a group or community that either results in, or has a high likelihood of resulting in injury, death, psychological harm, maldevelopment or deprivation ..." (2: 5). Injuries identified as violencerelated were divided into two major categories: assaults and self-harm. The definitions used for these two categories were drawn from the National Electronic Injury Surveillance System (NEISS) of the U.S. Consumer Product Safety Commission (4). The NEISS definition of assault-related injury is as follows: "Injury from an act of violence where physical force by [more than] 1 person is used with the intent of causing harm, injury, or death to another person; or an intentional poisoning by another person. This category includes perpetrators as well as intended and unintended victims of violent acts (e.g., innocent bystanders) ..." (4: 3).

The NEISS definition of a selfinflicted injury (confirmed or suspected) is: "Injury or poisoning resulting from a deliberate violent act inflicted on oneself with the intent to take one's own life or with the intent to harm oneself. This category includes suicide, suicide attempt, and other intentional self-harm ..." (4: 3).

\section{Data collection}

The cross-sectional data used in this study come from the VIVA surveillance system. The criteria for ED participation in the VIVA system included: (1) 24-hour operation; (2) location in a municipality with high injury rates (mortality and morbidity); (3) established status as a facility commonly treating injuries; and (4) participation in a care network or location in a municipality that participates in a care network for treating violence victims. Another criterion was geographic di- versity, to ensure a geographically diverse data set. Selected EDs meeting these criteria were invited to participate in the VIVA system; and those accepting received financial support from the Ministry of Health for the costs of the survey, staff training, etc. The resulting surveillance system covered 63 EDs representing $7.4 \%$ of all EDs linked to the public health system and 39 municipalities (where nearly $20 \%$ of the Brazilian population is concentrated), with at least one ED from each of the 26 states and the Federal District, and each of the capital cities except Porto Alegre, Belém, and São Paulo (which were not represented in the survey due to operational problems). Although the city of São Paulo was not represented, EDs in seven other cities in São Paulo State were included. Despite all of these efforts, the resulting data represent a convenience sample as opposed to a random sample of ED-treated injuries.

Due to the high number of ED visits, data were collected on an alternating schedule (day-shift/night-shift) in each participating ED. All injured patients admitted during a data collection period were interviewed by a trained health professional using a questionnaire. In some instances (such as when a victim was unconscious), a caretaker provided the responses. Variables collected by interview included victim demographics (sex, age, race, and education), type of transport used to go to the hospital, intentionality, type of injury (fall, burn, transport-related, assault, self-harm, or other), place of occurrence (home, street/public place, school, workplace, or other), and time of occurrence. Alcohol use by the victim (recorded as "yes" or "no") was queried in the interview, when suspected by the interviewers, based on major indicators. For assault-related cases, variables collected also included the relationship between the victim and the perpetrator(s), sex of the perpetrator(s), and number of perpetrators. The variables collected from medical records included main diagnosis, body part injured, and disposition. These variables were selected based on guidelines from WHO (5) and on data 
collection forms used in ED-based injury surveillance systems in other Latin American countries (allowing for comparisons to be made between the results of this study and those from other countries). Another reason for choosing these specific variables was their association with certain VRI risk factors (such as alcohol use) based on previous scientific literature.

The VIVA system was coordinated and implemented by state and municipal health department professionals who received training on injury surveillance concepts and use of the questionnaire, supplemented by written instructions. The study was reviewed and approved by Brazil's National Committee of Ethics in Research (CONEP).

\section{Data analysis}

Descriptive analysis. The descriptive analysis consisted of a series of twoway (marginal) tabulations. Selected characteristics of VRI cases were crosstabulated by sex of victim and also by type of violence (assault or self-harm).

Modeling. Logistic regression modeling was used for simultaneous assessment of the potential associations between type of violence (assault or self-harm) and multiple factors. A number of restrictions were imposed on the data used in this phase of the analysis. First, records for individuals less than 10 years old at the time of injury were excluded, as intentional selfharm is rarely observed among young children (and, for very young children, may not even be considered possible). Second, candidate modeling factors were required to have a data-value completeness rate of approximately $90 \%$ or higher (i.e., no more than $10 \%$ of reported cases with missing data values for each candidate factor). This criterion was established because the statistical modeling software (PROC GLIMMIX, a production version of the SAS GLIMMIX procedure for use with SAS version 9.1.3) (SAS Institute, Inc., Cary, North Carolina, USA) excludes records containing missing data for any analysis factor (6); employing a completeness requirement of $90 \%$ minimizes the amount of data lost to the modeling process. The candidate factors meeting this criterion and included in the modeling phase were sex, age in years, alcohol use ("yes" or "no"), and place of occurrence (collapsed to "home" versus "away"). Case records with missing data codes for any of these factors were excluded. Lastly, EDs reporting fewer than 20 cases meeting these criteria were excluded from this phase of the analysis. This restriction was applied in order to achieve computational stability during the model estimation process (which included an assessment of potential "group effects" within individual EDs). After applying these restrictions, a total of $n=3871$ case records representing 43 hospital EDs were available for the modeling phase.

Although education level was a candidate factor for the modeling phase, it was excluded in the analysis because data on education were missing for a substantial fraction of the case records (17.6\% for cases $25+$ years old). Moreover, the fact that younger cases systematically have lower levels of education would have further complicated the analysis. For these reasons, the education data were used only in the descriptive analysis.

The dichotomous outcome for the logistic regression model was coded as self-harm $=1$ and assault $=0$. In addition to the candidate factors mentioned above, a random intercept offset for each ED was included in the model to represent (at least in part) any group effect among the cases seen in the same $\operatorname{ED}(7,8)$.

The model-fitting process began with a semi-saturated model incorporating the fixed-effects factors sex, age, alcohol use, and place of occurrence, along with all two-way interactions between these factors, plus the random intercept offsets. A backward stepwise model reduction process was then employed, resulting in a final model incorporating all of these factors plus three interactions: sex by age, sex by alcohol use, and place of occurrence by age.
All factors considered in the modeling process were found to be significantly associated with type of violence, but not via main effects; each factor was involved in at least one significant (two-way) interaction. Consequently, model-estimated odds ratios for any factor are reported for specified levels of other factors.

\section{RESULTS}

A total of 47554 patients with injuries were registered in the VIVA system during the month of September 2006. Under the case definitions established above, 4835 of the registered injury cases were classified as violence-related and were thus included in the present study. VRI cases were reported by 62 of the 63 participating EDs (one ED did not report any VRI cases). The 4835 VRI cases included 3521 male victims $(72.8 \%)$ and 1314 female victims $(27.2 \%)$. Among all registered VRI cases, assaults accounted for 4417 $(91.4 \%)$ and self-inflicted injuries accounted for $418(8.6 \%)$. Approximately $86.7 \%$ of these injuries occurred in urban areas, whereas just $6.1 \%$ occurred in rural areas (with no data for 347 or $7.2 \%$ of cases) (data not shown).

\section{Descriptive analysis}

Table 1 shows the characteristics of VRI cases by sex of the victim. Victims were predominantly male, as reflected in an overall ratio of male to female cases ( $\mathrm{M} / \mathrm{F}$ ratio) of 2.7. Analysis by age group showed that the highest proportion of victims were 20-29 years old, followed by those 30-39 years old and 10-19 years old, respectively. The highest age-specific $\mathrm{M} / \mathrm{F}$ ratio was observed among individuals aged 60 years and over (4.9), and the lowest age-specific ratio was observed among children under 10 years of age (1.6).

Alcohol use was reported or suspected for a substantial proportion of victims, primarily males. Overall, violent acts most frequently took place in streets and public places, followed by residences. Schools accounted for a 
TABLE 1. Characteristics of violence-related injury cases seen in selected emergency departments, by sex of victim, (Brazil, September 2006) ${ }^{\mathrm{a}}$

\begin{tabular}{|c|c|c|c|c|c|c|c|}
\hline \multirow[b]{2}{*}{ Characteristic } & \multicolumn{2}{|c|}{ Male } & \multicolumn{2}{|c|}{ Female } & \multicolumn{2}{|c|}{ Total } & \multirow{2}{*}{$\begin{array}{c}\text { Male/female } \\
\text { ratio }^{b}\end{array}$} \\
\hline & Cases & $\%$ & Cases & $\%$ & Cases & $\%$ & \\
\hline \multicolumn{8}{|l|}{ Age $\left(\right.$ years) ${ }^{c}$} \\
\hline 0 to 9 & 138 & 4.0 & 88 & 6.7 & 226 & 4.7 & 1.6 \\
\hline 10 to 19 & 677 & 19.4 & 278 & 21.3 & 955 & 19.9 & 2.4 \\
\hline 20 to 29 & 1275 & 36.5 & 422 & 32.3 & 1697 & 35.4 & 3.0 \\
\hline 30 to 39 & 745 & 21.3 & 293 & 22.4 & 1038 & 21.6 & 2.5 \\
\hline 40 to 49 & 405 & 11.6 & 157 & 12.0 & 562 & 11.7 & 2.6 \\
\hline 50 to 59 & 147 & 4.2 & 48 & 3.7 & 195 & 4.1 & 3.1 \\
\hline$\geq 60$ & 103 & 3.0 & 21 & 1.6 & 124 & 2.6 & 4.9 \\
\hline Total & 3490 & & 1307 & & $4797^{d}$ & & 2.7 \\
\hline \multicolumn{8}{|l|}{ Alcohol ${ }^{\mathrm{C}}$} \\
\hline Yes & 1532 & 48.5 & 325 & 27.4 & 1857 & 42.7 & 4.7 \\
\hline No & 1628 & 51.5 & 860 & 72.6 & 2488 & 57.3 & 1.9 \\
\hline Total & 3160 & & 1185 & & 4345 & & \\
\hline \multicolumn{8}{|l|}{ Place of occurrence ${ }^{c}$} \\
\hline Street/public place & 1677 & 50.0 & 300 & 23.7 & 1977 & 42.8 & 5.6 \\
\hline Home & 724 & 21.6 & 744 & 58.7 & 1468 & 31.8 & 1.0 \\
\hline Workplace & 558 & 16.7 & 99 & 7.8 & 657 & 14.2 & 5.6 \\
\hline School & 82 & 2.4 & 45 & 3.5 & 127 & 2.7 & 1.8 \\
\hline Other & 310 & 9.3 & 80 & 6.3 & 390 & 8.4 & 3.9 \\
\hline Total & 3351 & & 1268 & & 4619 & & \\
\hline \multicolumn{8}{|l|}{ Mechanism of assaultc } \\
\hline Physical force/blunt object & 1362 & 42.1 & 621 & 58.9 & 1983 & 46.2 & 2.2 \\
\hline Cut/pierce & 963 & 29.7 & 199 & 18.9 & 1162 & 27.1 & 4.8 \\
\hline Firearm & 589 & 18.2 & 42 & 4.0 & 631 & 14.7 & 14.0 \\
\hline Sexual violence & 5 & 0.2 & 28 & 2.7 & 33 & 0.8 & 0.2 \\
\hline Other & 318 & 9.8 & 164 & 15.6 & 482 & 11.2 & 1.9 \\
\hline Total & 3237 & & 1054 & & 4291 & & 3.1 \\
\hline \multicolumn{8}{|l|}{ Relationship to victim (perpetrator) ${ }^{c}$} \\
\hline Stranger & 1380 & 48.6 & 198 & 21.0 & 1578 & 41.7 & 7.0 \\
\hline Acquaintance & 1126 & 39.6 & 337 & 35.7 & 1463 & 38.6 & 3.3 \\
\hline Parents/relatives & 336 & 11.8 & 410 & 43.4 & 746 & 19.7 & 0.8 \\
\hline Total & 2842 & & 945 & & 3787 & & \\
\hline \multicolumn{8}{|l|}{ Sex of perpetrator(s) } \\
\hline Male & 2477 & 89.7 & 696 & 74.9 & 3173 & 86.0 & 3.6 \\
\hline Female & 203 & 7.4 & 210 & 22.6 & 413 & 11.2 & 1.0 \\
\hline Male and female (i.e., multiple & & & & & & & \\
\hline perpetrators) & 81 & 2.9 & 23 & 2.5 & 104 & 2.8 & 3.5 \\
\hline Total & 2761 & & 929 & & 3690 & & \\
\hline \multicolumn{8}{|l|}{ Mechanism of self-harmc } \\
\hline Poisoning & 91 & 52.0 & 194 & 86.6 & 285 & 71.4 & 0.5 \\
\hline Cut/pierce & 40 & 22.9 & 17 & 7.6 & 57 & 14.3 & 2.4 \\
\hline Hanging/suffocation/strangulation & 10 & 5.7 & 2 & 0.9 & 12 & 3.0 & 5.0 \\
\hline Firearm & 8 & 4.6 & 2 & 0.9 & 10 & 2.5 & 4.0 \\
\hline Other & 26 & 14.9 & 9 & 4.0 & 35 & 8.8 & 2.9 \\
\hline Total & 175 & & 224 & & 399 & & 0.8 \\
\hline
\end{tabular}

low proportion of cases. The analysis of place of occurrence by sex of the victim revealed that $58.7 \%$ of the incidents among females occurred in the home, whereas $50.0 \%$ of incidents among males occurred in public places.
For assault-related cases, the most common mechanism of injury was physical force/blunt object ( $46.2 \%)$, followed by sharp objects (27.1\%). Firearms were used in $14.7 \%$ of these cases. More than half of the perpetrators in assault-related cases were known to the victims, with acquaintances accounting for $38.6 \%$ of the reported injuries and parents/relatives accounting for another $19.7 \%$. Strangers accounted for the remaining $41.7 \%$ of the assault- 
TABLE 2. Characteristics of assault and self-inflicted injury cases seen in selected emergency departments, Brazil, September 2006

\begin{tabular}{|c|c|c|c|c|c|c|}
\hline \multirow[b]{2}{*}{ Characteristic } & \multicolumn{2}{|c|}{ Assault } & \multicolumn{2}{|c|}{ Self-harm } & \multicolumn{2}{|c|}{ Total } \\
\hline & Cases & $\%$ & Cases & $\%$ & Cases & $\%$ \\
\hline \multicolumn{7}{|l|}{ Sex } \\
\hline Male & 3334 & 75.5 & 187 & 44.7 & 3521 & 72.8 \\
\hline Female & 1083 & 24.5 & 231 & 55.3 & 1314 & 27.2 \\
\hline Total & 4417 & & 418 & & 4835 & \\
\hline \multicolumn{7}{|l|}{ Education (persons $25+$ years old) } \\
\hline None & 178 & 8.9 & 20 & 9.3 & 198 & 9.0 \\
\hline 1 to 4 years & 560 & 28.1 & 52 & 24.1 & 612 & 27.7 \\
\hline 5 to 8 years & 633 & 31.8 & 71 & 32.9 & 704 & 31.9 \\
\hline 9 to 11 years & 536 & 26.9 & 58 & 26.9 & 594 & 26.9 \\
\hline$\geq 12$ years & 83 & 4.2 & 15 & 6.9 & 98 & 4.4 \\
\hline Total & 1990 & & 216 & & 2206 & \\
\hline \multicolumn{7}{|l|}{ Place of occurrence } \\
\hline Street/public place & 1940 & 46.0 & 37 & 9.2 & 1977 & 42.8 \\
\hline Home & 1125 & 26.7 & 343 & 84.9 & 1468 & 31.8 \\
\hline Workplace & 654 & 15.5 & 3 & 0.7 & 657 & 14.2 \\
\hline School & 124 & 2.9 & 3 & 0.7 & 127 & 2.7 \\
\hline Other & 372 & 8.8 & 18 & 4.5 & 390 & 8.4 \\
\hline Total & 4215 & & 404 & & 4619 & \\
\hline \multicolumn{7}{|l|}{ Alcohol use prior to incident } \\
\hline Yes & 1745 & 44.1 & 112 & 29.1 & 1857 & 42.7 \\
\hline No & 2215 & 55.9 & 273 & 70.9 & 2488 & 57.3 \\
\hline Total & 3960 & & 385 & & 4345 & \\
\hline \multicolumn{7}{|l|}{ Disposition } \\
\hline Treated and released/referred & 2801 & 67.0 & 188 & 48.0 & 2989 & 65.4 \\
\hline Admitted & 1300 & 31.1 & 195 & 49.7 & 1495 & 32.7 \\
\hline Died & 78 & 1.9 & 9 & 2.3 & 87 & 1.9 \\
\hline Total & 4179 & & 392 & & 4571 & \\
\hline
\end{tabular}

a Percentages based on number of records with data for tabulated characteristic.

related injuries. The $\mathrm{M} / \mathrm{F}$ ratio for victims was highest for cases perpetrated by strangers and lowest for cases perpetrated by parents/relatives. Most perpetrators were male $(86.0 \%)$, with females reported as perpetrators in just $11.2 \%$ of the cases (the remaining $2.8 \%$ of cases were attributed to multiple perpetrators of both sexes). The M/F ratio for victims was very different according to the sex of the perpetrator, with female perpetrators assaulting females relatively more often than male perpetrators assaulted females $(\mathrm{M} / \mathrm{F}$ victim ratios of 1.0 and 3.6, respectively).

Poisoning was the predominant mechanism for self-inflicted injuries, followed by cutting/piercing, suffocation/ hanging/strangulation, and firearms. The analysis of self-inflicted injury mechanism by sex showed marked differences. Poisoning was relatively more common among females $(86.6 \%$ of self-inflicted cases) than among males
(52.0\% of self-inflicted cases), whereas cutting/piercing, suffocation/hanging/ strangulation, and firearm use were relatively more common among males than females.

Table 2 presents a comparison of the characteristics of assault-related and self-inflicted injuries. There were notable differences in the distribution of cases by sex for the two types of violence. Victims in assault-related cases were predominantly male $(75.5 \%)$, while just over half $(55.3 \%)$ of the victims of self-harm were female. Figure 1 shows that for both types of violence (males and females combined) the highest proportion of cases occurred among 20-29 year olds.

For both assault-related and selfinflicted cases, the most frequently reported level of education (for persons $25+$ years old) was 5 to 8 years $(31.8 \%$ and $32.9 \%$, respectively); the proportion of people who declared having studied
12 years or more was slightly lower among victims of assault (4.2\%) than among victims of self-harm (6.9\%).

Streets and public places were the most frequent place of occurrence for assault-related injuries $(46.0 \%)$, whereas residences were the most frequent place of occurrence for self-inflicted injuries $(84.9 \%)$. Alcohol use was more commonly reported for assault victims than for victims of self-harm $(44.1 \%$ versus $29.1 \%$, respectively).

There were also notable differences in disposition for the two types of VRI cases. Most assault victims (67.0\%) were treated and released, whereas nearly half of the self-harm victims were hospitalized $(49.7 \%)$. The reported case fatality rate among those treated in the ED was slightly lower for assault-related injuries (1.9\%) than for self-inflicted injuries (2.3\%).

The distribution of the number of assault and self-harm cases by hour of 
FIGURE 1. Assaults and self-inflicted injury seen in selected emergency departments, by age group, Brazil, September 2006

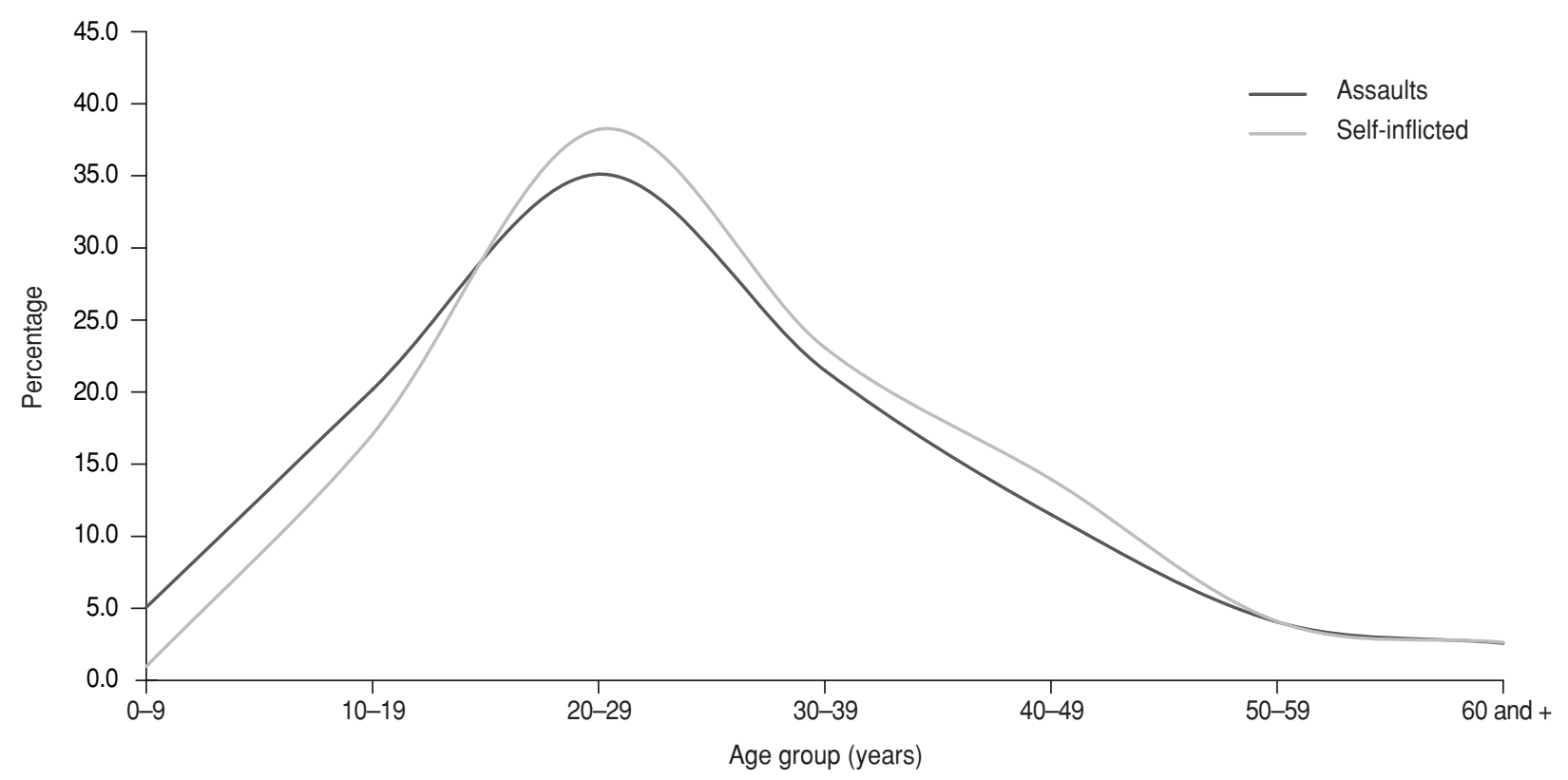

occurrence (data not shown) showed a similar pattern for both types of VRIs. The highest number of cases occurred between 4:00 pm and midnight, decreasing after that. For both assaults and self-harm injuries, the lowest number of occurrences was at 6:00 am.

\section{Modeling}

The fitted logistic regression model permits estimation of odds ratios (ORs) for self-harm versus assault, controlling for and conditioned on other factors. The ORs in Table 3a show how the type of violence varies according to the sex of the victim, simultaneously conditioned on age and alcohol use. Because age was entered into the model as a continuous variable, model-based ORs were estimated for the specific ages of 20,35 , and 50 years old, which were considered representative of a broad subsection of the total range of ages. Among persons 20 years old presenting with VRIs, females were significantly more likely to have been victims of selfharm than males. (Equivalently, 20year-old males were more likely to have been victims of assault than females.) This finding is consistent irrespective of alcohol use, but it is more prominent among cases where alcohol use was reported (ORs of 3.44 and 1.74, respectively). Among persons 35 years old presenting with VRIs, females were significantly more likely to have been victims of self-harm than males (equivalently, males were more likely to have been victims of assault than females) only when alcohol use was reported. Among persons 50 years old presenting with VRIs, no significant differences in the type of violence were noted between females and males.

The ORs in Table $3 b$ show how the type of violence varies according to place of occurrence, conditioned on the age of the victim. Among persons presenting with VRIs, those injured at home were significantly more likely to have been victims of self-harm (as opposed to assault) than those injured away from home. This finding was consistent across the range of ages considered, but was most prominent for the youngest cases (20 year olds) (OR of 17.72).

\section{DISCUSSION}

Injury surveillance data collected in EDs are an important complement to existing national data sources covering
VRIs in Brazil. Previous assessments of the problem of violence have been limited to mortality and hospitalization data. While important, such data do not describe the full extent of VRIs in Brazil or the full burden these injuries impose on the nation's healthcare system. While less severe than that of mortality or hospitalization, the VRI public health burden is relatively high due to the number of VRIs treated in EDs. VRIs are also risk factors and/or markers for more serious injuries in the future. The additional information provided by ED injury surveillance thus helps strengthen the epidemiological basis for evaluating violence prevention programs and policies (9).

The results of this study substantiate the large impact of VRIs on Brazilian males and young adults; these demographic groups are overrepresented among VRI victims seen in EDs relative to their prevalence in the population. The study data indicate that although males only represent $49.2 \%$ of the Brazilian population, they accounted for $72.8 \%$ of violent injury ED cases (3). Similarly, 20-29 year olds accounted for $35.4 \%$ of violent injury ED cases, while only representing $17.7 \%$ of the population (3). Mortality 
TABLE 3a. Odds ratios comparing male and female violence-related injury cases seen in selected emergency departments, Brazil, September 2006

\begin{tabular}{|c|c|c|c|}
\hline Age (years) & Alcohol use & Female vs. male o & ds ratio (self-harm, assault) \\
\hline 20 & $\begin{array}{l}\text { Yes } \\
\text { No }\end{array}$ & $\begin{array}{l}3.44 \\
1.74\end{array}$ & $\begin{array}{l}(2.06,5.75)^{a, b} \\
(1.19,2.53)^{a, b}\end{array}$ \\
\hline 35 & $\begin{array}{l}\text { Yes } \\
\text { No }\end{array}$ & $\begin{array}{l}2.42 \\
1.22\end{array}$ & $\begin{array}{l}(1.52,3.85)^{a, b} \\
(0.87,1.70)^{a}\end{array}$ \\
\hline 50 & $\begin{array}{l}\text { Yes } \\
\text { No }\end{array}$ & $\begin{array}{l}1.70 \\
0.86\end{array}$ & $\begin{array}{l}(0.93,3.09)^{a} \\
(0.51,1.43)^{a}\end{array}$ \\
\hline
\end{tabular}

a $95 \%$ confidence interval.

${ }^{b}$ Odds ratios significantly different than the null value of 1.0 .

TABLE 3b. Odds ratios comparing "home" and "away" violence-related injury cases seen in selected emergency departments, Brazil, September 2006

\begin{tabular}{crl}
\hline Age (years) & "Home" vs. "away" odds ratio (self-harm, assault) \\
\hline 20 & 17.72 & $(11.67,26.90)^{\mathrm{a}, \mathrm{b}}$ \\
35 & 12.22 & $(8.68,17.20)^{\mathrm{a}, \mathrm{b}}$ \\
50 & 8.43 & $(4.76,14.93)^{\mathrm{a}, \mathrm{b}}$ \\
\hline
\end{tabular}

a $95 \%$ confidence interval.

${ }^{\mathrm{b}}$ Odds ratios significantly different than the null value of 1.0 .

data and hospitalization data from public hospitals in Brazil indicate similarly high proportions (and rates) of VRIs among these groups $(10,11)$.

VRIs treated in EDs in Brazil are predominantly due to assaults involving adolescent and younger adult male victims, and often occur in streets or other public places. This finding was anticipated, based on previously documented patterns of violence-related mortality and morbidity in Brazil (11), and is consistent with public perceptions of urban violence in the country. Although this study did not allow for examination of the causes of this pattern, research on violence involving young urban males from other parts of the world suggests that a range of factors (12-15) associated with economic inequity play an important role in hindering the healthy social development of innercity children and adolescents, thus contributing to violence. Programs and policies that address these factors and reduce isolation from positive influences and opportunities offer the best hope of curbing the global problem of youth violence.

Physical force or the use of blunt objects, followed by cutting and piercing instruments and firearms, were the three leading mechanisms of VRI treated in EDs $(46.2 \%, 27.1 \%$, and $14.7 \%$, respectively). These findings differ from mortality data in which firearms are the lead cause of homicides in Brazil (11).

After streets and other public places, residences were the most common location for VRIs treated in EDs (31.8\%), despite the perception that the home is a safe place. Common forms of violence that often occur in the home are intimate partner violence and child maltreatment. Although VRIs perpetrated by intimate partners could not be explicitly identified, the study results showed that the majority of incidents among females $(58.7 \%)$ occurred in the home. In addition, women were more likely to suffer an injury at the hands of a parent or relative than from acquaintances or strangers $(43.4 \%$ versus $35.7 \%$ and $21.0 \%$, respectively).
WHO estimates indicate the prevalence of lifetime physical and sexual violence by an intimate partner is $27 \%$ in rural areas and $34 \%$ in urban areas of Brazil $(16,17)$. Strategies to prevent the perpetration of violence in the family are thus a crucial component of overall violence prevention efforts.

The results from this study showed that ED staff suspected that $42.7 \%$ of patients seen for VRIs were under the influence of alcohol. This finding is consistent with numerous studies that have documented an association between alcohol use and many kinds of injury $(18,19)$. Results from the WHO collaborative study on alcohol and injuries at three EDs in Latin America found that the risk of a VRI increased with drinking, and that $36 \%$ of injury patients in Brazil had used alcohol sometime during the six hours prior to the injury (20). In Cali, Colombia, almost half of the VRI victims treated in an ED were suspected or declared to be under the influence of alcohol (21). To address this issue, some areas of Brazil are instituting interventions. For example, a law was implemented in Diadema City (São Paulo State) in 2002 prohibiting bars from selling alcoholic beverages after 11:00 pm, resulting in a significant decrease in murders (22).

In Brazil, due to the high homicide rates and public concerns about violence, suicides have not been a public health priority. Data from Brazil's Mortality Information System (SIM), however, show that there were 8550 suicide victims nationally in 2005, and that the highest proportion of cases and greatest risk was among adults 20-29 years old (3). Prior research has demonstrated that suicide attempts and other self-inflicted injuries are a major risk factor for completed suicide $(23,24)$. Consequently, identifying injuries as self-inflicted and intervening with appropriate medical and psychological treatment is an important strategy for preventing further suicide attempts and completed suicides.

The findings from the logistic regression analysis help to clarify some important differences in the epidemiologic patterns of assault and self- 
inflicted injury. The results indicate, for example, that women were more likely to be victims of self-inflicted injury than men, and that this tendency was stronger the younger they were and when alcohol was involved. This finding complements research indicating women are more likely to attempt suicide than men (25), suggesting that, at least in Brazil, this tendency is influenced by age and alcohol use. In addition, self-inflicted injuries were more likely to occur at home than were assault-related injuries, which were more likely to happen in streets/public places, and this tendency, while consistent across all ages, was again more pronounced among younger victims.

The patterns of VRI in this study were similar to those reflected in injury statistics for other countries of the region. For example, in this study, most ED visits for VRIs were due to assault (4 417, or $91.4 \%$ of all cases), similar to the results of a study carried out in a single hospital in Colombia (21), which found that $95.3 \%$ of VRI-related visits to the ED were due to assault. By comparison, nationally representative data for the United States for the year 2004 indicate that $77.5 \%$ of nonfatal VRIs treated in EDs were due to assault (24), somewhat lower than the percentage observed in this study. Homicide rates in Brazil and Colombia are also consistently higher than in the United States (4). On the other hand, this study's finding that physical force or a blunt object was the leading mechanism of assault-related injury is similar to results in the United States (4, 24), Colombia (21), Nicaragua (25), and Canada (26). Also, similar to the results of this study, poisoning has been found to be the leading mechanism for self-inflicted injuries in the United States (4, 24), Colombia (21), and Nicaragua (25). Further studies are needed to better understand the determinants of these similarities and differences.

There are several important limitations to the data collected for this study. First, the completeness and uniformity of reporting has not been evaluated. Several EDs reported very few
VRI cases of any type, whereas others reported large numbers of VRI cases but relatively few due to self-harm. About $34.0 \%(n=1501)$ of the assaultrelated cases were reported by 10 EDs; these same 10 EDs reported $10.0 \%$ ( $n=$ 42) of the self-inflicted injury cases. Second, it must be recognized that although the EDs participating in the surveillance effort are broadly representative geographically, they nevertheless constitute a convenience sample. For this reason, the data are not appropriate for purposes of estimating national population-based rates, and the study findings must be considered in this context.

The manner in which information on alcohol use was collected (by interview or based on suspected use) is another limitation of the study. Further, the literature suggests that studying the association between alcohol and injury in EDs may be difficult, even when based on blood alcohol concentration (BAC), the most accurate test, because many factors can interfere with the results (27). Among such factors are the severity of the injury (patients that are more severely injured may be more likely to test positive than the less severely injured, because they often arrive at the ED sooner); the type and location of emergency services; the length of time between admission to the ED and the BAC estimate, etc. (27). Despite these limitations, alcohol is a major risk factor for injury, and many studies have shown the importance of evaluating the role of alcohol use in VRIs (28).

Among the study's strengths was the type and quality of data generated by the VIVA system, which included relatively detailed information on a large number of VRI cases over a short time period, providing key findings on recent patterns of injury in Brazil to help guide prevention efforts at local and country levels. Some of this data, such as information on place of occurrence, alcohol use, and type of perpetrator, has not been readily available previously and may be useful for planning strategies for prevention programs. Another benefit of this study stems from the process of estab- lishing the VIVA system, which helped identify and involve many health professionals across Brazil in injury prevention. Health professionals, particularly those in EDs, are in a unique position to provide support, assistance, and protection, as they frequently are among the first to see and interact with victims of violence.

Future iterations of the VIVA system should consider the possibility of implementing a data collection system based on random sampling of EDs in Brazil rather than on convenience sampling. This would have two critical advantages. First, the data could also be used to generate national estimates. Second, such estimates could be used in conjunction with population data to estimate population-based rates, thereby enabling assessment of the risk of various types of injuries presenting to EDs in subgroups of the Brazilian population. These very important public health indicators (i.e., population-based estimates and measures of risk) cannot be reliably generated using a convenience sample. An essential step to facilitate random sampling would be the establishment of a registry of all EDs in Brazil. A model for this type of ED injury surveillance system is provided by NEISS (4).

\section{CONCLUSION}

Males comprised the majority of VRI cases seen at selected EDs in Brazil. VRIs among male victims were predominantly due to assaults, whereas such injuries among female victims were due to self-harm slightly more frequently than to assaults. Alcohol appears to play a role in VRIs, as a large proportion of cases involved the suspected use of alcohol.

The new VIVA system provided relatively detailed data on a large number of VRI cases. The results will improve understanding of the scope and characteristics of VRIs in Brazil, providing timely information that will contribute to national injury prevention efforts. These data are also very valuable for identifying important areas for future research. 


\section{REFERENCES}

1. Centers for Disease Control and Prevention (US). Homicide trends and characteristicsBrazil, 1980-2002. MMWR Morb Mortal Wkly Rep. 2004;53(8):169-71.

2. Krug EG, Dahlberg LL, Mercy JA, Zwi AB, Lozano $R$, editors. World report on violence and health. Geneva: World Health Organization; 2002.

3. Ministry of Health (BR), Public Health Service, Department of Informatics [statistics on the Internet]. São Paulo: DATASUS; 2007 [cited 2007 March 13]. Available from: www. datasus.gov.br.

4. Vyrostek SB, Annest JL, Ryan GW. Surveillance for fatal and nonfatal injuries-United States, 2001. MMWR Surveill Summ. 2004; 53(7):1-57.

5. Holder Y, Peden M, Krug E, Lund J, Gururaj G, Kobusingye O, editors. Injury surveillance guidelines. Geneva: World Health Organization; 2001.

6. SAS Institute Inc. Production GLIMMIX Procedure (PROC GLIMMIX), June 2006 [software package/documentation on the Internet]. Cary (NC): SAS Institute, Inc.; 2006 [downloaded 2007 July 6]. Available from: http://support. sas.com/rnd/app/da/glimmix.html.

7. Agresti A. An introduction to categorical data analysis. 2nd ed. Hoboken (NJ): Wiley; 2007.

8. McCulloch CE, Searle SR. Generalized, linear, and mixed models. New York: Wiley; 2001.

9. Stone DH, Morrison A, Smith GS. Emergency department injury surveillance systems: the best use of limited resources? Inj Prev. 1999; 5(3):166-7

10. Souza ER, Lima MLC. The panorama of urban violence in Brazil and its capitals. Cienc Saude Coletiva. 2006;11(2):363-73.

11. Gawryszewski VP, Rodrigues EMS. The burden of injury in Brazil, 2003. Sao Paulo Med J. 2006;124(4):208-13.
12. Reiss AJ, Roth JA, editors. Understanding and preventing violence. Washington: National Academy Press; 1993.

13. Sampson RJ, Raudenbush S, Earls F. Neighborhoods and violent crime: a multilevel study of collective efficacy. Science. 1997;277:918-24.

14. Mercy JA. Assaultive violence and war. In: Levy BS, Sidel VW, editors. Social injustice and public health. New York: Oxford University Press; 2006. p. 294-317.

15. Wilson WJ. The truly disadvantaged: the inner city, the underclass, and public policy. Chicago: University of Chicago Press; 1987.

16. Schraiber LB, D'Oliveira AFPL, Couto MT. [Violence and health: recent scientific studies]. Rev Saude Publica. 2006;40 Spec no. 7:112-20.

17. García-Moreno C, Jansen HA, Ellsberg M, Heise L, Watts C. WHO multi-country study on women's health and domestic violence against women. Summary report of initial results on prevalence, health outcomes and women's responses. Geneva: World Health Organization; 2005. (WHO/FCH/GWH/03).

18. Maio FR, Cunningham RE. The spectrum of alcohol problems and the scope of emergency medicine practice. In: Hungerford DW, Pollock DA, editors. Alcohol problems among emergency department patients: proceedings of a research conference on identification and intervention. Atlanta: Centers for Disease Control and Prevention; 2002. p. 21-31.

19. Watt K, Purdie DM, Roche AM, McClure R. Injury severity: role of alcohol, substance use and risk-taking. Emerg Med Australas. 2006; 18(2):108-17.

20. Borges G, Orozco R, Cremonte M, Buzi-Figlie N, Cherpitel C, Poznyak V. Alcohol and violence in the emergency department: a regional report from the WHO collaborative study on alcohol and injuries. Salud Publica Mex. 2008; 50 Suppl 1:S6-11.
21. Bejarano M, Rendon LF, Rojas MC, Durán CA, Albornoz M. Intent-associated factors in injuries of external cause. Rev Colomb Cir. 2006;21(4):215-24.

22. Duailibi S, Ponicki W, Grube J, Pinsky I, Laranjeira R, Raw M. The effect of restricting opening hours on alcohol-related violence. Am J Public Health. 2007;97(12):2276-80.

23. De Leo D, Bertolote J, Lester D. Self-directed violence. In: Krug E, Dahlberg LL, Mercy JA, Zwi AB, Lozano R, editors. World report on violence and health. Geneva: World Health Organization; 2002. p. 185-212.

24. Centers for Disease Control and Prevention (US). WISQARS(tm) [Web-based Injury Statistics Query and Reporting System] [interactive database on the Internet]. Atlanta: CDC, 2007 [cited 2007 May 14]. Available from: http://www.cdc.gov/ncipc/wisqars.

25. Espitia-Hardeman V, Rocha J, Clavel-Arcas V, Dahlberg L, Mercy JA, Concha-Eastman A. Characteristics of nonfatal injuries in Leon Nicaragua-2004. Int J Inj Contr Saf Promot. 2007;14(2):69-75.

26. Snider CE, Lee JS. Emergency department dispositions among 4100 youth injured by violence: a population-based study. CJEM. 2007; 9(3):164-9.

27. Casswell S, Humphrey G, Rankine J, Pledger $\mathrm{M}$. WHO collaborative study on alcohol and injuries. Final report. Geneva: World Health Organization; 2007.

28. Kaysen D, Dillworth TM, Simpson T, Waldrop A, Larimer ME, Resick PA. Domestic violence and alcohol use: trauma-related symptoms and motives for drinking. Addict Behav. 2007; 32(6):1272-83. Epub 2006 Nov 13.

Manuscript received on 10 October 2007. Revised version accepted for publication on 26 June 2008.
RESUMEN

\section{Lesiones relacionadas con la violencia en los servicios de emergencia de Brasil}

Palabras clave
Objetivos. Se describen las características de los casos de lesiones relacionadas con la violencia (LRV) que se presentan en los servicios de emergencia en Brasil y se comparan las circunstancias de los casos relacionados con asaltos y los autoinfligidos.

Métodos. En este estudio de corte transversal se describen los casos atendidos en septiembre de 2006 en 62 servicios de emergencia de 26 estados y el Distrito Federal. Se analizaron 4835 casos por medio de tabulaciones estadísticas básicas y se evaluó mediante análisis de regresión logística la posible asociación entre los tipos de violencia (asalto o lesión autoinfligida) y diversos factores.

Resultados. De los casos, 72,8\% eran hombres y 35,4\% tenían entre 20 y 29 años. Se informó o sospechó del consumo de bebidas alcohólicas en 42,7\% de ellos, más frecuentemente en hombres. De los casos, 91,4\% eran víctimas de asaltos y 8,6\% de lesiones autoinfligidas. Tres cuartas partes de las víctimas de asaltos eran hombres y la mitad de las lesiones autoinfligidas fueron en mujeres. El principal mecanismo de asalto fue la fuerza física/objetos romos $(46,2 \%)$, mientras que el veneno fue el mecanismo predominante en las lesiones autoinfligidas $(71,4 \%)$. Las mujeres jóvenes presentaron una probabilidad significativamente mayor de haber sufrido lesiones autoinfligidas que los hombres jóvenes, mientras que estos tuvieron una mayor probabilidad de haber sido víctimas de asaltos, especialmente cuando se informó de consumo de alcohol. Las lesiones autoinfligidas tuvieron una probabilidad significativamente mayor de ocurrir en el hogar, mientras que los asaltos fueron más probables fuera de casa.

Conclusiones. Estos resultados pueden ayudar a comprender mejor el alcance y las características de las LRV en Brasil -y así contribuir a los esfuerzos nacionales de prevención de lesiones- y a identificar nuevas áreas de investigación.

Servicios médicos de urgencia, emergencias, violencia, agresión, suicidio, Brasil. 